Int. J. Dev. Biol. 52: 545-550 (2008)

doi: $10.1387 / \mathrm{ijdb} .072557 \mathrm{jw}$

\title{
Renovation of the egg extracellular matrix at fertilization
}

\author{
JULIAN L. WONG and GARY M. WESSEL* \\ Department of Molecular Biology, Cellular Biology, and Biochemistry, Brown University, Providence, RI, USA
}

\begin{abstract}
Extracellular matrices are essential for cell survival and function. This is especially relevant for eggs, which establish a physical barrier at fertilization to protect a new embryo from additional sperm and pathogens. Formation of an extracellular matrix is most dramatic in sea urchins, in which fertilization was first observed in animals with the "sudden appearance of a perfectly transparent envelope" (A. Derbès, 1847). The process of assembling this extracellular "envelope" has been a topic of intense study ever since. Here we integrate the cellular and molecular events necessary to form this fertilization envelope within the first few minutes of a new embryo's life.
\end{abstract}

KEY WORDS: hydrogen peroxide, peroxidase, transglutaminase, protease, cortical granule, dual oxidase

\section{Introduction}

Most cells within an animal body are in contact with an extracellular matrix. This heterogeneous environment participates in signaling to and from the cell, functions as adhesive substrates for movement or tension, and protects the cell. Nowhere is the function of protection more evident than at fertilization, when the egg modifies its extracellular matrix to block supernumerary sperm from reaching the egg cell surface. Despite the diversity in morphology, molecular composition, and mechanism of renovation following fertilization across species, the ultimate role of these extracellular matrices is highly conserved: eggs with aberrant matrices are subject to multiple sperm fusions, leading to irregular cell division and eventual embryonic death (comparatively reviewed in Wong and Wessel, 2006a).

The sea urchin fertilization envelope is a classic representative of the protective function of an extracellular matrix. It serves as the first indication of sperm-mediated egg activation, described by Derbès as a "circular line" encompassing the egg following fertilization (Derbès, 1847; Briggs and Wessel, 2006). Immediately after its formation, this fertilization envelope is further challenged in the open ocean by thousands of sperm, microbes, and high shear force. Thus, the formation and stability of this matrix is essential for the survival of the early sea urchin embryo.

The sea urchin egg has selected for an extracellular matrix with several critical properties that ensure its timely formation, including: 1) Speed of modification. The sea urchin egg extracellular matrix is called the vitelline layer, a nascent scaffold used to assemble the final product, the fertilization envelope. The fertili- zation envelope is constructed within about thirty seconds of sperm fusion, a rate that is essential for its role in the blockage of other sperm. It should be noted that this animal also has an electrical block to sperm fusion. This temporary change in electrical potential across the plasma membrane occurs within milliseconds of the first sperm fusion, and inhibits the fusion of any subsequent sperm for 60 seconds; after this window, the membrane potential returns to pre-fertilization levels that are compatible with sperm fusion. The 60-second duration, though, is sufficient to prevent additional sperm fusion since fertilization envelope assembly requires half of that time to complete. 2) Separation from the egg cell surface. During its construction, the vitelline layer is lifted off the surface of the egg, separating it from the plasma membrane by tens of microns (depending on the species). This process has obvious benefits in distancing sperm and microbes from the egg, but it complicates the logistics. Somehow construction occurs while the vitelline layer scaffold is expanding its surface area by as much as $400 \%$ - all within the 30 seconds of construction. The force necessary for this lifting is thought to be a result of the hydration of glycosaminoglycans secreted at fertilization (Schuel et al., 1974), but separation also requires proteolysis of linkages that anchor the scaffold to the egg plasma membrane (Carroll and Epel, 1975a; Haley and Wessel, 1999). 3) Stabilization. Within minutes of assembly, proteins of the fertilization envelope are covalently joined to each other to form a large and stable macromolecular structure. This new extracellular matrix is both mechanically and biochemically stable (Shapiro, 1975; Just, 1939; Wong et al., 2004; Harvey, 1909). Indeed, it takes a unique and specific protease to free the developing

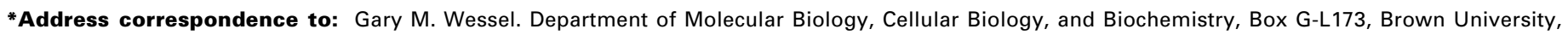
Providence, RI 02912, USA. Fax: +1-401-863-2421. e-mail: rhet@brown.edu
}

Published online: 4 July 2008

0214-6282/2008/\$35.00

(c) UBC Press

Printed in Spain 
embryo from this shell for further development (Mozingo et al., 1993; Lepage and Gache, 1989, 1990; Nomura et al., 1997). 4) Filtration. The fertilization envelope establishes a diffusion limit of approximately $40 \mathrm{kDa}$ (Wong and Wessel, 2008; Kay and Shapiro, 1985). (By comparison, the kidney glomerulus, the major blood filtration organ of vertebrates, achieves a filtration limit of approximately $69 \mathrm{kDa}$ - the molecular mass and globular radius of serum albumin - through a dynamic interface established by extracellular matrix proteins and cellular remodeling (Patari-Sampo et al., 2006; Chang et al., 1975)). Given the environment in which the sea urchin embryo develops, this limited permeability may be important for establishing an embryonic microenvironment free of microbial toxins or harmful pathogens. This review will emphasize both the classical studies and recent molecular details regarding the fertilization envelope that help us understand the extracellular architecture that enhances the reproductive success of the sea urchin.

\section{Construction of the Fertilization Envelope}

The fertilization envelope is constructed from two protein populations (Fig. 1). The unfertilized egg has a nascent extracellular matrix referred to as the vitelline layer, upon which other proteins are added during a secretory process that occurs after fertilization. Of the estimated twenty-five major glycoproteins in the sea urchin vitelline layer (Gache et al., 1983; Niman et al., 1984; Longo, 1981), two are known and, consistent with historical biochemical data, are sensitive to disulfide reducing agents (Aketa and Tsuzuki, 1968; Chandler and Heuser, 1980; Tegner and Epel, 1976; Epel et al., 1970; Carroll et al., 1977). The two vitelline layer proteins identified are enriched in CUB domains (originally found in complement factors $\mathrm{Clr}$ and Cls, urchin EGF, and bone morphogenetic protein 1 ), motifs of an anti-parallel $\beta$ strand fold that are stabilized by up to four positionally conserved disulfide bonds (Bork and Beckmann, 1993; Romero et al., 1997; Varela et al., 1997). These domains have been shown to homoor heterodimerize to form carbohydrate-binding pockets or protein-interactive surfaces, and are found in extracellular proteins throughout animal phylogeny (Romero et al., 1997; Varela et al., 1997).

The two CUB-containing proteins within the vitelline layer include p160, a 160-kDa post protein clustered at the tips of microvilli (Haley and Wessel, 2004), and rendezvin ${ }^{120}$, the egg extracellular matrix splice-variant of the oocyte-specific rendezvin gene (Wong and Wessel, 2006b) [see Box 1 below]. p160 contains 5 CUB domains and anchors the vitelline layer to the egg plasma membrane. Cleavage of this linker protein must occur in order for the vitelline layer scaffold to separate from the egg surface (Haley and Wessel, 2004). The protease responsible for this cleavage appears to be CGSP1, the serine protease that resides within the cortical granules (Haley and Wessel, 1999, 2004). Unlike the proteolyzed fragments of $p 160$, rendezvin ${ }^{120}$ is retained in the modified egg ECM after it lifts off the egg surface (Wong and Wessel, 2006b), serving as a core scaffold that organizes fertilization envelope assembly (Carroll et al., 1986; Ruiz-Bravo etal., 1986; Kay and Shapiro, 1985). It too has several CUB domains, and we hypothesize that it associates directly with p160 to remain anchored to the egg surface. This binding may occur directly through the CUB domains, forming heterodimers, or indirectly, by a lectin function of CUB dimers for binding to other glycoproteins (Romero et al., 1997; Varela et al., 1997; Bork and Beckmann, 1993). Different from most extracellular matrices, the vitelline layer of the egg is synthesized with the anticipated function of separating from the plasma membrane. Thus, the points of anchorage appear to be limited to enable rapid separation of the vitelline layer scaffold from the egg surface at fertilization.

The second major contribution in construction of the fertilization envelope is the contents of the cortical granules. Cortical granules are secretory vesicles synthesized during oogenesis and released following gamete fusion (reviewed in Wessel et al., 2001). These oocyte- and egg-specific organelles number up to 15,000 per sea urchin egg (Laidlaw and Wessel, 1994), and are enriched within the distal region of the egg's cortex, subjacent to the plasma membrane. Sea urchin cortical granule membranes are hemifused to the plasma membrane, making them primed for content release upon exposure to an appropriate concentration of their calcium trigger (Wong et al., 2007). The shear number of granules per egg and their rapid secretion en masse following fertilization implies that cortical granule contents can significantly alter the local extracellular environment upon exocytosis, easily transforming a sperm-competent egg vitelline layer into a physical barrier against additional sperm.

The major mass of protein released from the sea urchin cortical granules is non-enzymatic and contributes significantly to the permanent block to polyspermy. Of the 12 different proteins secreted by the cortical granules (Wessel et al., 2001), the six major proteins visible by Coomassie staining are directly incorporated into the fertilization envelope (Wong and Wessel, 2004). Five genes encode these cortical granule proteins, including proteoliaisin (Somers et al., 1989; Somers and Shapiro, 1991), sfe1 (Wessel et al., 2000; Laidlaw and Wessel, 1994), sfeg (Wessel, 1995; Laidlaw and Wessel, 1994), rendezvin(Wong and Wessel, 2006b) [see Box 1 below], and the enzyme ovoperoxidase (LaFleur et al., 1998; Nomura and Suzuki, 1995; Nomura et al., 1999). These six proteins rapidly self-assemble within the vitelline layer scaffold to form the fertilization envelope (Fig. 1). These high affinity interactions are likely due to the tandem arrangement of common protein-binding domains in all these proteins: proteoliaisin, SFE1, and SFE9 are abundant in low density lipoprotein receptor type $\underline{A}$ (LDLrA) repeats - containing up to 28 tandem LDLrA repeats, in some orthologs (Wessel et al., 2000; Wessel, 1995; Wong and Wessel, 2004) whereas the cortical granule members of the rendezvin family are, like their vitelline layer sibling

BOX 1: The rendezvin protein family has a complex series of processing and distribution events. The full-length rdztranscript is alternatively spliced into at least three forms, with the most abundant pool of mRNA encoding the parent of cortical granule-destined rendezvin ${ }^{60}$ and rendezvin ${ }^{90}$ (Wong and Wessel, 2006b). Two significantly less-abundant transcripts are also created, encoding the vitelline layer-destined rendezvin ${ }^{120}$. During posttranslational processing, $\mathcal{S}$. purpuratus rendezvin ${ }^{60}$ is cleaved from its carboxy-terminal partners (cortical granule rendezvin ${ }^{90}$ or vitelline layer rendezvin ${ }^{120}$ ). Differential trafficking of each variant follows secretory paths for their respective destinations. Amazingly, after fertilization these segregated siblings reunite within the fertilization envelope. 


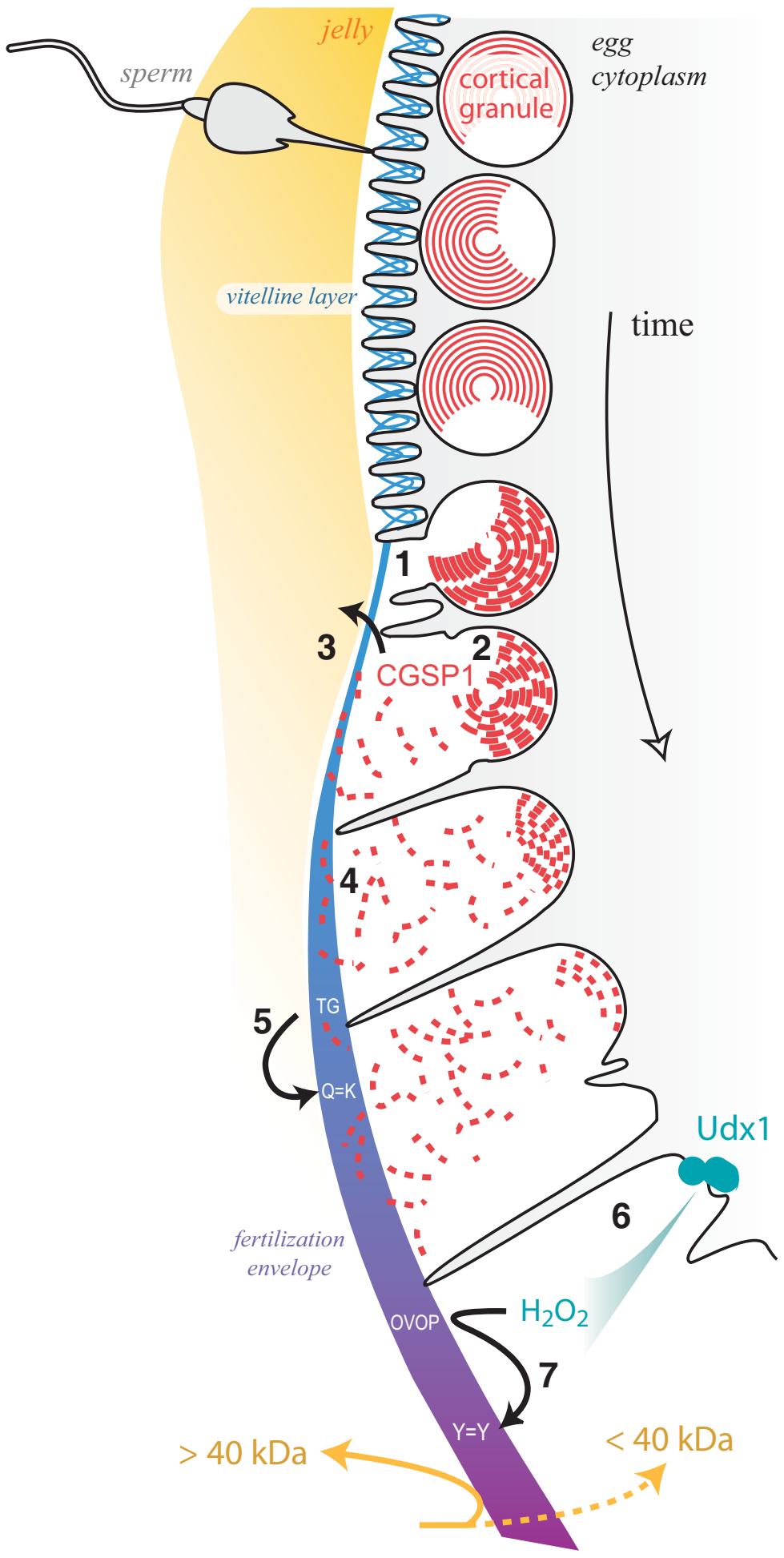

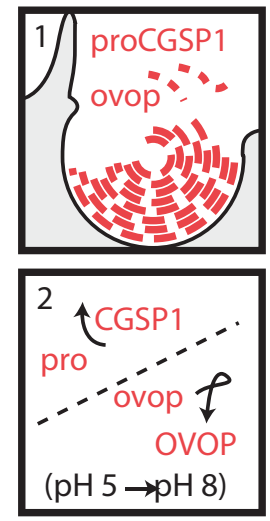

cortical granule exocytosis

alkaline autoactivation of cortical granule enzymes
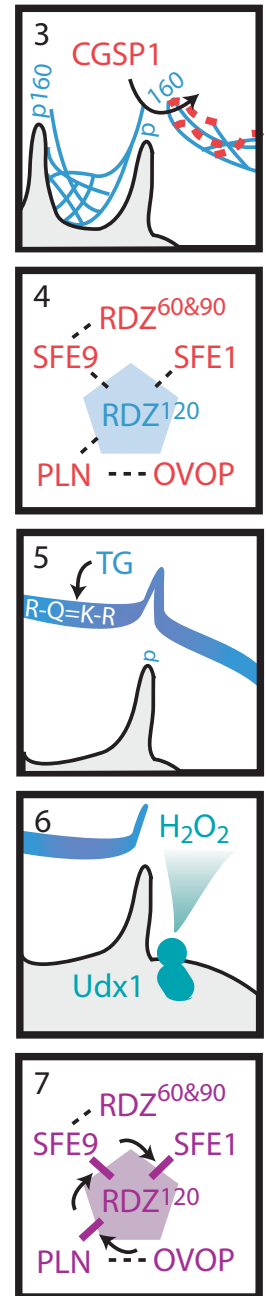

auto-assembly of cortical granule proteins into the vitelline layer

hydrogen peroxide synthesis

proteolysis of transmembrane anchors

transamidation

dityrosine crosslinking

Fig. 1. Milestones of fertilization envelope formation. Diagram detailing the time-course of modification of the egg cortex and fertilization envelope assembly, starting from sperm fusion (top) to ovoperoxidase-dependent crosslinking (bottom). Milestones are highlighted, and are described in the text. In panel (7), arrows denote dityrosine crosslinks formed by active ovoperoxidase. Abbreviations: CGSP1, cortical granule serine protease 1 (proCGSP1 = zymogenic form); OVOP, ovoperoxidase (ovop = zymogenic form); TG, transglutaminase; Udx1, urchin dual oxidase 1; RDZ, rendezvin; $P L N$, proteoliaisin; $\mathrm{H}_{2} \mathrm{O}_{2}$, hydrogen peroxide; " $R-Q=K-R$ ", covalent epsilon(gamma-glutamyl)lysine bonds; " $R-Y=Y-R$ ", covalent dityrosine crosslink; $40 \mathrm{kDa}$, macromolecules of 40,000 daltons. (Modified with permission from Wong and Wessel, 2008). 
rendezvin ${ }^{120}$, abundant in CUB domains (Wong and Wessel, 2006b) [see Box 1]. Although CUB domains and LDLrA repeats are common throughout the animal kingdom where they function in protein-protein binding, the fertilization envelope provides the first direct evidence that proteins with these two modules interact in a specific, high-affinity manner (Song et al., 2006).

Proteolysis is one enzymatic activity considered to be conserved in the block to polyspermy (Carroll and Epel, 1975b; 1975a; Runnstrom, 1966; Vacquier et al., 1973). Many functions have been ascribed to a cortical granule-derived protease, including removal of the sperm receptor, modification of the vitelline layer, and even egg activation (Carroll and Epel, 1975a; Carroll and Jaffe, 1995; Runnstrom, 1966; Vacquier et al., 1973) - yet it appears that only one enzyme is responsible for all activities. The cortical granule serine protease (CGSP1) is the only protease activity detected from sea urchin cortical granules (Carroll and Epel, 1975a; Haley and Wessel, 1999). Furthermore, CGSP1 activity at the egg surface appears to be selective, suggesting that it has specific roles and/or regulators that are not required at any other time during development (Haley and Wessel, 1999). Of the 200-300 estimated proteins at the egg cell surface, this protease cleaves and liberates peptides from approximately $15 \%$ of the total population (Carroll and Epel, 1981; Shapiro, 1975). Cleaving the vitelline post protein $\mathrm{p} 160$, for example, separates 85,60 , and $35 \mathrm{kDa}$ peptides of the ectodomain from its transmembrane domain (Haley and Wessel, 2004), thus permitting the physical detachment of the vitelline layer from the egg surface during the formation of the fertilization envelope (Kay and Shapiro, 1985).

The sea urchin fertilization envelope is also mechanically transformed from a flexible network of glycoproteins into a hardened shell. This physical transformation is a consequence of enzymatic activity including transglutaminase and peroxidase. Transglutaminase catalyzes isopeptide amide bonds between glutamine and lysine, thereby fusing adjacent proteins to one another (Lorand and Graham, 2003; Battaglia and Shapiro, 1988; Nemes et al., 2005). This extended family of calcium-dependent enzymes generates intermolecular bonds through a cysteineprotease-like catalytic mechanism (reviewed in Lorand and Graham, 2003; Nemes et al., 2005). A zymogenic form of transglutaminase appears to reside at the sea urchin egg surface and is activated within 1 minute following cortical granule exocytosis (Battaglia and Shapiro, 1988). This activity generates isopeptide bonds necessary for stabilizing the initial fertilization envelope assembly (Battaglia and Shapiro, 1988; Kay and Shapiro, 1985; Cariello et al., 1994). Curiously, transglutaminase activity requires cortical granule exocytosis, suggesting that its zymogen is activated by CGSP1 proteolysis - a similar phenomenon for the activation of homologs such as transglutaminase type 3 and plasma factor XIIla (Lorand and Graham, 2003; Nemes et al., 2005).

While transglutaminase activity is necessary for fertilization envelope resilience (Cariello et al., 1994), matrix rigidity is primarily established by peroxidase activity (Showman and Foerder, 1979; Wong and Wessel, 2008). Peroxidases catalyze the formation of dityrosine bonds between adjacent proteins through a freeradical intermediate that originates from hydrogen peroxide (Gross, 1959). The hydrogen peroxide is synthesized by members of a specific family of enzymes e.g. the Nox family (Lambeth, 2002; Lambeth et al., 2007). The source of the sea urchin hydrogen peroxide is a single enzyme member of the dual oxidase (Duox) family of enzymes. This sea urchin dual oxidase Udx1 is present at the egg cell surface and is activated by calcium fluxes within the cytoplasm as a result of sperm activation (Wong et al., 2004). Duoxes are transmembrane enzymes with a peroxidase (hydrogen peroxide consumer) domain at their amino termini, and an NADPH-dependent oxidase domain (hydrogen peroxide generator) at their carboxy-termini (Lambeth et al., 2007; Lambeth, 2002). The function of the amino terminal peroxidase domain is unclear, but its similarity to catalases suggests that it may be important for neutralizing stray hydrogen peroxide before the reactive molecule can damage the embryo (Wong et al., 2004). The NADPH oxidase domain utilizes the cofactor NADPH as an electron donor, and is activated by calcium, presumably through the EF-hands located in the cytoplasm between the peroxidase and oxidase domains (Lambeth et al., 2007; Wong et al., 2004). While steric conformational changes that occur following calcium binding are hypothesized to enable enzyme activation, exactly how calcium regulates this or any other Duox is unknown.

In the sea urchin egg, the cortical granule-derived ovoperoxidase consumes the hydrogen peroxide generated by Udx1 in order to establish mechanical and chemical resilience in the sea urchin fertilization envelope (Showman and Foerder, 1979; Foerder and Shapiro, 1977; Hall, 1978; Bryan, 1970). This myeloperoxidaselike family of enzymes is specifically transcribed in oocytes, and packaged into cortical granules (LaFleur et al., 1998; Nomura and Suzuki, 1995). When released from the cortical granule lumen, ovoperoxidase is drawn away from the egg surface by the tethering protein, proteoliaisin, that keeps the enzyme associated with the elevating vitelline layer, thereby restricting its cross-linking activity to the ECM undergoing modification (Somers et al., 1989; Mozingo et al., 1994).

The chemistry of the peroxidase-mediated dityrosine crosslinking process was recently exploited to identify ovoperoxidase protein substrates within the fertilization envelope (Wong and Wessel, 2008). A fluorophore-conjugated tyramide molecule from the tyramide signal amplification mechanism (Bobrow et al., 1989) was used to compete with the formation of endogenous dityrosine crosslinks, thereby covalently labeling the protein substrate and enabling the proteins of the fertilization envelope to remain separable by SDS-PAGE. These targets were then identified by immunoblotting and tandem mass spectrometry. Surprisingly, these results show that the free-radical crosslinking mechanism in the sea urchin egg extracellular is remarkably selective and is capable of distinguishing target proteins derived from the same gene family. All of the LDLrAcontaining proteins (proteoliaisin, SFE1, SFE9) are cross-linked to the vitelline layer rendezvin ${ }^{120}$ whereas the cortical granulederived rendezvin ${ }^{60}$ and rendezvin ${ }^{90}$ remain free, both intra- and inter-molecularly (Wong and Wessel, 2008). The relationship between binding affinity and crosslinking of cortical granule proteins with rendezvin ${ }^{120}$ is consistent with the high percentage of tyrosine residues in this isoform (Wong and Wessel, 2006b). From the perspective of ovoperoxidase, this specificity implies that either 1) free radical production is exquisitely localized, enabling only a specific population of crosslinks to be made, or 2) ovoperoxidase-dependent free radical production is ubiquitous, but the intermediates react very specifically such that subtle structural differences within the hierarchy of protein-protein inter- 
actions dictate selectivity of crosslinking. Although the binding interactions between the different proteins that constitute the fertilization envelope are known, we do not yet know if the molecular structure of this matrix can distinguish between these two models describing how the specificity of free radical crosslinking is achieved.

\section{Implications}

At the level of the single cell, the paradoxical relationship between conservation of function and sequence radiation is best exemplified by the constituents of the physical block to polyspermy (Wong and Wessel, 2006a). Yet the implications for the simplicity of interacting partners and biochemical modifications that occur to this extracellar matrix extend well into embryogenesis and adult tissue. For example, the more high-affinity interacting domains a protein retains, the more freedom a structurally unrelated domain in that same protein would have to diverge without losing affinity for its original binding partner. Thus, minor alterations to an otherwise conserved protein foundation can greatly expand the functionality and flexibility of an extracellular matrix, possibly resulting in diversification and specialization of the tissues that rely on these evolving matrices. Some cases where this can be seen in action include protein superfamilies such as laminin, fibronectin, and collagen, whose members are used throughout the animal kingdom in matrices as diverse as the basal lamina to tendons and ligaments.

\section{References}

AKETA, K., AND TSUZUKI, H. (1968) Sperm-binding capacity of the S-S reduced protein of the vitelline membrane of the sea urchin egg. Exp Cell Res 50:675676.

BATTAGLIA, D.E., AND SHAPIRO, B.M. (1988) Hierarchies of protein cross-linking in the extracellular matrix: involvement of an egg surface transglutaminase in early stages of fertilization envelope assembly. J Cel/ Bio/ 107:2447-2454.

BOBROW, M.N., HARRIS, T.D., SHAUGHNESSY, K.J., AND LITT, G.J. (1989) Catalyzed reporter deposition, a novel method of signal amplification. Application to immunoassays. J Immunol Methods 125:279-285.

BORK, P., AND BECKMANN, G. (1993) The CUB domain. A widespread module in developmentally regulated proteins. $J$ Mo/ Bio/231:539-545.

BRIGGS, E., AND WESSEL, G.M. (2006) In the beginning.animal fertilization and sea urchin development. Dev Bio/300:15-26.

BRYAN, J. (1970) On the reconstitution of the crystalline components of the sea urchin fertilization membrane. $J$ Cell Bio/45:606-614.

CARIELLO, L., ZANETTI, L., AND LORAND, L. (1994) Effects of inhibiting transglutaminase during egg fertilization and development. Biochem Biophys Res Commun 205:565-569.

CARROLL, D.J., ACEVEDO-DUNCAN, M., JUSTICE, R.W., AND SANTIAGO, L. (1986) Structure, assembly and function of the surface envelope (fertilization envelope) from eggs of the sea urchins, Strongylocentrotus purpuratus. $A d v$ Exp Med Bio/207:261-291.

CARROLL, D.J., AND JAFFE, L.A. (1995) Proteases stimulate fertilization-like responses in starfish eggs. Dev Bio/170:690-700.

CARROLL, E.J., JR., BYRD, E.W., AND EPEL, D. (1977) A novel procedure for obtaining denuded sea urchin eggs and observations on the role of the vitelline layer in sperm reception and egg activation. Exp Cell Res 108:365-374.

CARROLL, E.J., JR., AND EPEL, D. (1975a) Elevation and hardening of the fertilization membrane in sea urchin eggs. Role of the soluble fertilization product. Exp Cell Res 90:429-432.

CARROLL, E.J., JR., AND EPEL, D. (1975b) Isolation and biological activity of the proteases released by sea urchin eggs following fertilization. Dev Bio/44:22-32.
CARROLL, E.J., JR., AND EPEL, D. (1981) Reevaluation of cell surface protein release at fertilization and its role in regulation of sea urchin egg protein synthesis. Dev Bio/87:374-378.

CHANDLER, D.E., AND HEUSER, J. (1980) The vitelline layer of the sea urchin egg and its modification during fertilization. A freeze-fracture study using quickfreezing and deep-etching. $J$ Cell Bio/84:618-632.

CHANG, R.L., UEKI, I.F., TROY, J.L., DEEN, W.M., ROBERTSON, C.R., AND BRENNER, B.M. (1975) Permselectivity of the glomerular capillary wall to macromolecules. II. Experimental studies in rats using neutral dextran. Biophys J15:887-906.

DERBÈS, A. (1847) Observations sur le mecanisme et les phenomenes qui accompagnent la formation de l'embryon chezl'oursin comestible. Ann Sci Nat Zoo/8:80-98.

EPEL, D., WEAVER, A.M., AND MAZIA, D. (1970) Methods for revoval of the vitelline membrane of sea urchin eggs. I. Use of dithiothreitol (Cleland Reagent). Exp Cell Res 61:64-68.

FOERDER, C.A., AND SHAPIRO, B.M. (1977) Release of ovoperoxidase from sea urchin eggs hardens the fertilization membrane with tyrosine crosslinks. Proc Nat/ Acad Sci USA 74:4214-4218

GACHE, C., NIMAN, H.L., AND VACQUIER, V.D. (1983) Monoclonal antibodies to the sea urchin egg vitelline layer inhibit fertilization by blocking sperm adhesion. Exp Cell Res 147:75-84.

GROSS, A.J. (1959) The oxidation of tyramine, tyrosine, and related compounds by peroxidase. J Biol Chem 234:1611-1614.

HALEY, S.A., AND WESSEL, G.M. (1999) The cortical granule serine protease CGSP1 of the sea urchin, Strongylocentrotus purpuratus, is autocatalytic and contains a low-density lipoprotein receptor-like domain. Dev Bio/211:1-10.

HALEY, S.A., AND WESSEL, G.M. (2004) Proteolytic cleavage of the cell surface protein $\mathrm{p} 160$ is required for detachment of the fertilization envelope in the sea urchin. Dev Bio/272:191-202.

HALL, H.G. (1978) Hardening of the sea urchin fertilization envelope by peroxidasecatalyzed phenolic coupling of tyrosines. Cel/15:343-355.

HARVEY, E.N. (1909) The mechanism of membrane formation and other early changes in developing sea urchins' eggs as bearing on the problem of artificial parthenogenesis. JExp Zoo/8:355-376.

JUST, E.E. (1939) The Biology of the Cell Surface. P. Blackiston's Song \& Company, Philadelphia, PA.

KAY, E.S., AND SHAPIRO, B.M. (1985) The formation of the fertilization membrane of the sea urchin egg. In: Metz, C.B., and Monroy, A. (eds) Biology of fertilization. Academic Press Inc., Orlando, FL, pp. 45-80.

LAFLEUR, G.J., JR., HORIUCHI, Y., AND WESSEL, G.M. (1998) Sea urchin ovoperoxidase: oocyte-specific member of a heme-dependent peroxidase superfamily that functions in the block to polyspermy. Mech Dev 70:77-89.

LAIDLAW, M., AND WESSEL, G.M. (1994) Cortical granule biogenesis is active throughout oogenesis in sea urchins. Development 120:1325-1333.

LAMBETH, J.D. (2002) Nox/Duox family of nicotinamide adenine dinucleotide (phosphate) oxidases. Curr Opin Hemato/9:11-17.

LAMBETH, J.D., KAWAHARA, T., AND DIEBOLD, B. (2007) Regulation of Nox and Duox enzymatic activity and expression. Free Radic Biol Med43:319-331.

LEPAGE, T., AND GACHE, C. (1989) Purification and characterization of the sea urchin embryo hatching enzyme. J Biol Chem 264:4787-4793.

LEPAGE, T., AND GACHE, C. (1990) Early expression of a collagenase-like hatching enzyme gene in the sea urchin embryo. Embo J9:3003-3012.

LONGO, F.J. (1981) Effects of concanavalin A on the fertilization of sea urchin eggs Dev Bio/82:197-202.

LORAND, L., AND GRAHAM, R.M. (2003) Transglutaminases: crosslinking enzymes with pleiotropic functions. Nat Rev Mol Cell Bio/4:140-156.

MOZINGO, N.M., HOLLAR, L.R., AND CHANDLER, D.E. (1993) Degradation of an extracellular matrix: sea urchin hatching enzyme removes cortical granulederived proteins from the fertilization envelope. J Cell Sci104 (Pt 3):929-938.

MOZINGO, N.M., SOMERS, C.E., AND CHANDLER, D.E. (1994) Ultrastructure of the proteoliaisin-ovoperoxidase complex and its spatial organization within the Strongylocentrotus purpuratus fertilization envelope. JCel/Sci107 (Pt 10):27692777.

NEMES, Z., PETROVSKI, G., CSOSZ, E., AND FESUS, L. (2005) Structure- 
function relationships of transglutaminases-a contemporary view. Prog Exp Tumor Res 38:19-36.

NIMAN, H.L., HOUGH-EVANS, B.R., VACQUIER, V.D., BRITTEN, R.J., LERNER, R.A., AND DAVIDSON, E.H. (1984) Proteins of the sea urchin egg vitelline layer. Dev Biol 102:390-401.

NOMURA, K., HOSHINO, K., AND SUZUKI, N. (1999) The primary and higher order structures of sea urchin ovoperoxidase as determined by cDNA cloning and predicted by homology modeling. Arch Biochem Biophys 367:173-184.

NOMURA, K., SHIMIZU, T., KINOH, H., SENDAI, Y., INOMATA, M., AND SUZUKI N. (1997) Sea urchin hatching enzyme (envelysin): cDNA cloning and deprivation of protein substrate specificity by autolytic degradation. Biochemistry 36:7225-7238.

NOMURA, K., AND SUZUKI, N. (1995) Sea urchin ovoperoxidase: solubilization and isolation from the fertilization envelope, some structural and functional properties, and degradation by hatching enzyme. Arch Biochem Biophys 319:525-534

PATARI-SAMPO, A., IHALMO, P., AND HOLTHOFER, H. (2006) Molecular basis of the glomerular filtration: nephrin and the emerging protein complex at the podocyte slit diaphragm. Ann Med 38:483-492.

ROMERO, A., ROMAO, M.J., VARELA, P.F., KOLLN, I., DIAS, J.M., CARVALHO, A.L., SANZ, L., TOPFER-PETERSEN, E., AND CALVETE, J.J. (1997) The crystal structures of two spermadhesins reveal the CUB domain fold. Nat Struct Bio/ 4:783-788.

RUIZ-BRAVO, N., ROSSIGNOL, D.P., DECKER, G., ROSENBERG, L.I., AND LENNARZ, W. (1986) Characterization of the Strongylocentrotus purpuratus egg cell surface receptor for sperm. Adv Exp Med Bio/207:293-313.

RUNNSTROM, J. (1966) The vitelline membrane and cortical particles in sea urchin eggs and their function in maturation and fertilization. Adv Morphog 5:221-325.

SCHUEL, H., KELLY, J.W., BERGER, E.R., AND WILSON, W.L. (1974) Sulfated acid mucopolysaccharides in the cortical granules of eggs. Effects of quaternary ammonium salts on fertilization. Exp Cell Res 88:24-30.

SHAPIRO, B.M. (1975) Limited proteolysis of some egg surface components is an early event following fertilization of the sea urchin, Strongylocentrotus purpuratus. Dev Bio/46:88-102.

SHOWMAN, R.M., AND FOERDER, C.A. (1979) Removal of the fertilization membrane of sea urchin embryos employing aminotriazole. Exp Cell Res 120:253-255

SOMERS, C.E., BATTAGLIA, D.E., AND SHAPIRO, B.M. (1989) Localization and developmental fate of ovoperoxidase and proteoliaisin, two proteins involved in fertilization envelope assembly. Dev Bio/131:226-235.
SOMERS, C.E., AND SHAPIRO, B.M. (1991) Functional domains of proteoliaisin, the adhesive protein that orchestrates fertilization envelope assembly. $J$ Biol Chem 266:16870-16875.

SONG, J., L, WONG, J., L, AND WESSEL, G., M, (2006) Oogenesis: Single cell development and differentiation. Dev Bio/300:385-405

TEGNER, M.J., AND EPEL, D. (1976) Scanning electron microscope studies of sea urchin fertilization. I. Eggs with vitelline layers. J Exp Zoo/197:31-57.

VACQUIER, V.D., TEGNER, M.J., AND EPEL, D. (1973) Protease released from sea urchin eggs at fertilization alters the vitelline layer and aids in preventing polyspermy. Exp Cell Res 80:111-119.

VARELA, P.F., ROMERO, A., SANZ, L., ROMAO, M.J., TOPFER-PETERSEN, E., AND CALVETE, J.J. (1997) The 2.4 A resolution crystal structure of boar seminal plasma PSP-I/PSP-II: a zona pellucida-binding glycoprotein heterodimer of the spermadhesin family built by a CUB domain architecture. $J \mathrm{Mol} B \mathrm{Bi} /$ 274:635-649.

WESSEL, G.M. (1995) A protein of the sea urchin cortical granules is targeted to the fertilization envelope and contains an LDL-receptor-like motif. Dev Biol 167:388-397.

WESSEL, G.M., BROOKS, J.M., GREEN, E., HALEY, S., VORONINA, E., WONG, J., ZAYDFUDIM, V., AND CONNER, S. (2001) The biology of cortical granules. Int Rev Cyto/209:117-206.

WESSEL, G.M., CONNER, S., LAIDLAW, M., HARRISON, J., AND LAFLEUR, G.J., JR. (2000) SFE1, a constituent of the fertilization envelope in the sea urchin is made by oocytes and contains low-density lipoprotein-receptor-like repeats. Biol Reprod 63:1706-1712.

WONG, J., L, AND WESSEL, G., M, (2008) Free-radical crosslinking of specific proteins alters the function of the egg extracellular matrix at fertilization. Development 135: 431-440.

WONG, J.L., CRÉTON, R., AND WESSEL, G.M. (2004) The oxidative burst at fertilization is dependent upon activation of the dual oxidase Udx1. Dev Cell 7:801-814.

WONG, J.L., KOPPEL, D.E., COWAN, A.E., AND WESSEL, G.M. (2007) Membrane hemifusion is a stable intermediate of exocytosis. Dev Cel/12:653-659.

WONG, J.L., AND WESSEL, G.M. (2004) Major components of a sea urchin block to polyspermy are structurally and functionally conserved. Evo/Dev6:134-153.

WONG, J.L., AND WESSEL, G.M. (2006a) Defending the zygote: Search for the ancestral animal block to polyspermy. Curr Top Dev Bio/72:1-151.

WONG, J.L., AND WESSEL, G.M. (2006b) Rendezvin: An essential gene encoding independent, differentially-secreted egg proteins that organize the fertilization envelope proteome following self-association. Mol Biol Cel/17:5241-5252. 


\section{Related, previously published Int. J. Dev. Biol. articles}

See our recent Special Issue Developmental Biology in Poland edited by Tarkowski, Maleszewski and Kloc at: http://www.ijdb.ehu.es/web/contents.php?vol=52\&issue=2-3

See our recent Special Issue Ear Development edited by Fernando Giraldez and Bernd Fritzsch at: http://www.ijdb.ehu.es/web/contents.php?vol=51\&issue=6-7

Mammalian fertilization: the egg's multifunctional zona pellucida Paul M. Wassarman and Eveline S. Litscher Int. J. Dev. Biol. (2008) Vol. 52 (doi: 10.1387/ijdb.072524pw)

Allorecognition mechanisms during ascidian fertilization Yoshito Harada and Hitoshi Sawada

Int. J. Dev. Biol. (2008) Vol. 52: (doi: 10.1387/ijdb.072544yh)

Distinct mechanisms underlie sperm-induced and protease-induced oolemma block to sperm penetration.

Sebastian Komorowski, Katarzyna Szczepanska and Marek Maleszewski Int. J. Dev. Biol. (2003) 47: 65-69

Sperm-egg interaction at fertilization: glycans as recognition signals. F Rosati, A Capone, C D Giovampaola, C Brettoni and R Focarelli Int. J. Dev. Biol. (2000) 44: 609-618

Calcium in sea urchin egg during fertilization.

I Gillot, P Payan, J P Girard and C Sardet

Int. J. Dev. Biol. (1990) 34: 117-125

2006 ISI ${ }^{* *}$ Impact Factor $=3.577^{\star *}$

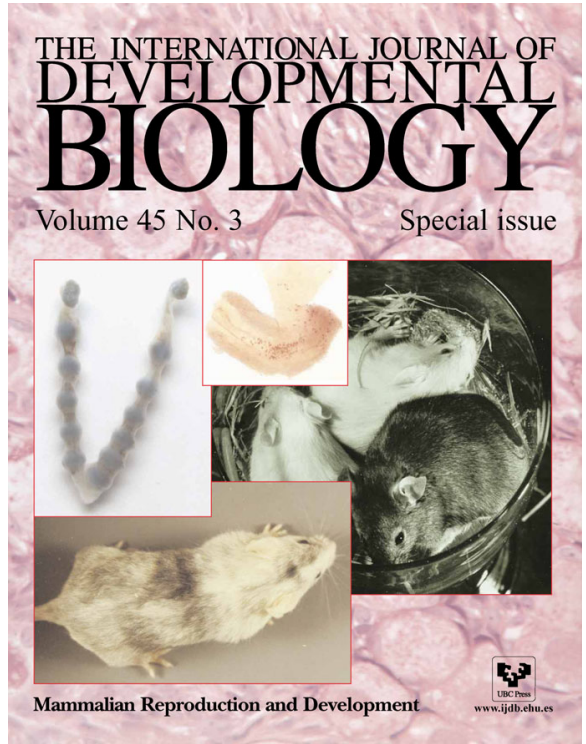

